\title{
Edith Stein e suas contribuições para a psicologia
}

\author{
Edith Stein and her contributions to psychology
}

\section{Suzana Filizola Brasiliense Carneiro, Andrés Eduardo Aguirre Antúnez}

Universidade de São Paulo, SP, Brasil

\section{Resumo}

Este artigo tem como objetivo ilustrar as contribuições de Edith Stein para a Psicologia a partir de uma pesquisa empírica que buscou compreender o processo formativo dos moradores de uma região periférica de Salvador. Para tanto, apresenta os resultados de uma análise, baseada na obra Contribuições à fundamentação filosófica da Psicologia e das Ciências do Espírito, que ilustra o percurso individual de três participantes da pesquisa. A análise possibilita identificar cinco vivências comuns (vivências psicofísicas de forte intensidade; vivência do limite pessoal; vivência da escuta de si; vivência da luta interior; e vivência de uma decisão livre) que marcam o processo de transformação dos sujeitos, orientados por um projeto pessoal. Exemplifica, deste modo, a contribuição da fenomenologia de Edith Stein para a Psicologia no sentido de não reduzir a pessoa aos desafios do contexto em que vive ou aos condicionamentos psicofísicos aos quais está submetida, mas a enxergá-la na sua inteireza, discriminando as diferentes naturezas de vivências e o seu modo singular de viver, com a potência que ele contém.

Palavras-chave: Edith Stein. Psicologia. Violência. Alagados. Formação Humana.

* SFBC: Doutora em Ciências, e-mail: sf.carneiro@uol.com.br AEAA: Doutor em Psiquiatria e Psicologia médica, e-mail: antunez@usp.br 


\section{Abstract}

This article aims to illustrate the contributions of Edith Stein to Psychology from an empirical research that sought to understand the formative process of the residents of a peripheral region of Salvador. To do so, it presents the results of an analysis, based on the work "Contributions to the philosophical foundation of Psychology and the Sciences of the Spirit", which illustrates the individual course of three participants of the research. The analysis makes it possible to identify five common experiences (psychophysical lived experiences of high intensity, lived experience of the personal limit, lived experience of listening to oneself, lived experience of inner struggle, and lived experience of a free decision) that mark the process of transformation of subjects, guided by a personal project. It thus exemplifies the contribution of Edith Stein's phenomenology to psychology in order not to reduce the person to the challenges of the context in which it live or to the psychophysical conditioning to which it is subjected, but to see it in its entirety by discriminating the different natures of experiences and their unique way of living, with the power it contains.

Keywords: Edith Stein. Psychology. Violence. Alagados. Human formation.

\section{Introdução ${ }^{1}$}

A proximidade de Edith Stein com a Psicologia se evidencia desde a época em que era estudante universitária em Breslau, quando participou dos seminários de William Stern (1871-1938). Stein buscava nesta nova ciência a possibilidade de uma investigação científica da subjetividade, mas acabou se deparando com uma psicologia restrita ao estudo das sensações corpóreas e daquilo que era possível captar a partir do método experimental, sem conseguir acessar o espírito humano.

Edith Stein irá encontrar na fenomenologia de Edmund Husserl o caminho investigativo adequado para o seu objeto de estudo e, ao contrário do que se possa pensar, o percurso filosófico da autora não a distanciou da psicologia, mas promoveu uma nova forma de

1 Apoio FAPESP. 
aproximação, agora com o intuito de colaborar com esta disciplina, individuando conceitos fundamentais com os quais trabalhava e sobre os quais, ainda hoje, nem sempre os psicólogos possuem a devida clareza. A este respeito Stein (1999a) afirma reconhecer os esforços da psicologia em esclarecer o conceito de "psíquico", mas entende que estes esforços são viciados por um erro básico que é a confusão entre "consciência" - referente ao "eu puro"; objeto da fenomenologia - e "psíquico" - referente ao eu empírico; objeto da psicologia (STEIN, 1999a, p. 41-57).

As contribuições de Edith Stein para o problema em questão encontram-se, sobretudo, na obra Contribuições à fundamentação filosófica da Psicologia e das Ciências do Espírito ${ }^{2}$, onde ela dialoga com representantes da psicologia de seu tempo (Bergson, Lipps, Wundt), e o faz a partir de um tema importante debatido à época que era o da causalidade psíquica (ALES BELLO, 2015). Nesta obra Stein (1999a) afirma a insuficiência do modelo de causalidade da física para a compreensão dos fenômenos da interioridade e entende que para investigar a natureza da causalidade psíquica é necessário ir à raiz do fenômeno, ou seja, "observar a relação causal operando no interior da psique" (ALES BELLO, 1999, p. 11). Para tanto, reconhece a necessidade de individuar o que é a psique, diferenciando-a da consciência e da vida do espírito, o que ela fará pela descrição fenomenológica do fluxo originário da consciência (vivências puras); da vida psíquica (estados vitais) e da vida espiritual (vivências intencionais), colocando em evidência a natureza da relação causal em cada um destes âmbitos; ou a sua inexistência, no caso das vivências puras (STEIN, 1999a).

No âmbito da realidade psíquica, Stein (1999a) reconhece uma qualidade permanente na sucessão de estados vitais em constante transformação. Trata-se da força vital, cujo aumento ou diminuição provoca mudanças nas outras qualidades psíquicas, sendo por isso reconhecida como a causa do processo psíquico. Stein (1999a) conclui

2 Tradução do título original Beiträge zur philosophischen Begründung der Psychologie und der Geisteswissenschaften. Na referência bibliográfica consta a tradução italiana intitulada Psicologia e Scienze dello Spirito: Contributi per uma fondazione filosofica. 
que não existe realidade psíquica sem causalidade, pois se "falta a força vital necessária não há a possibilidade de constituição de uma psique com qualidades e estado reais" (STEIN, 1999a, p. 65). Por outro lado, reconhece que se trata de uma relação causal de tipo qualitativo, impossível de quantificar ou fazer prognósticos precisos extraindo leis gerais. Isto devido à impossibilidade de identificar precisamente a relação entre os graus de tensão da força vital e os sentimentos vitais (que revelam o estado atual do eu) e ainda, porque a força vital varia de indivíduo para indivíduo.

No âmbito das vivências intencionais (vida espiritual), Stein (1999a) reconhece que a ligação entre os atos se dá pela motivação e que esta conexão acontece pelo sentido de determinado ato e não pelo cumprimento do ato em si. Tal constatação demonstra a importância de se buscar acessar a interioridade da pessoa, evitando interpretações superficiais baseadas nos comportamentos e não nas motivações.

Por fim, Stein (1999a) coloca em evidência a unidade da pessoa a partir da relação entre a força vital e a motivação. Em linhas gerais, podemos dizer que a motivação aponta para uma ação em determinada direção, ou seja, está relacionada a uma força de orientação, mas que é necessária uma quantidade mínima de força vital para que a ação ocorra.

Esta análise de Edith Stein denuncia, portanto, a fragilidade de uma psicologia que pretenda se apoiar no modelo das ciências naturais, iludindo-se na falsa segurança da previsibilidade, das generalizações ou de qualquer tipo de teorização que prescinda de um olhar para a vivência singular de cada pessoa. Ao mesmo tempo, apura o olhar para o reconhecimento das diferentes qualidades de vivências, auxiliando o psicólogo a captar as nuances dos movimentos pessoais de seus pacientes e a identificar se eles são fruto de reações psicofísicas ou de um posicionamento espiritual do eu.

Pesquisas recentes na área da Psicologia demonstram que os desafios apontados não foram totalmente superados. Cardoso (2012), por exemplo, problematiza a falta de consenso a respeito do objeto e método da Psicologia Científica Moderna e afirma que o enfrentamento de temáticas com as quais esta disciplina se depara ainda hoje, tais como determinismo versus livre arbítrio e nativismo versus empirismo, 
evidencia a necessidade de uma fundamentação antropológica que ilumine os aspectos essenciais do ser humano. Segundo Cardoso (2012), somente assim será possível superar concepções ingênuas e dicotômicas que dificultam o amadurecimento da Psicologia.

As consequências práticas destas concepções são exemplificadas por Silva (2011) que, ao estudar o contexto da Saúde Mental na Estratégia de Saúde da Família (ESF) aponta para a necessidade de superar a lógica individualista, a tendência a generalizações, a discriminação das diversidades existentes nas experiências humanas e a redução dos usuários do serviço a um diagnóstico médico. A este respeito, o psiquiatra italiano Bruno Callieri, em consonância com o pensamento de Edith Stein, afirma que a singularidade de cada ser humano é irredutível e se expressa inclusive nos distúrbios mentais (ALES BELLO, 2013). Ele afirma:

[...] ninguém possui a permissão epistemológica de violar conceitualmente a liberdade do tu com o qual nos deparamos ou que vem até nós, de deduzir de leis pré-estabelecidas o comportamento em uma dada situação, de ler o "sintoma" pelo reconhecimento de padrões rigidamente fixados (CALLIERI, 2012, p. 637).

De acordo com Ales Bello (2011) este olhar para a singularidade possibilita o encontro com a pessoa, "mesmo na aparente estranheza das suas estruturas constitutivas" (CALLIERI, 2012, p. 649). Deste modo, as alterações patológicas podem ser compreendidas como possibilidades humanas, como variações do nosso mundo e não como algo distante, estranho a nós (ALES BELLO, 2013).

No campo clínico há necessidade de se ampliar a noção de psicoterapia para além da mera compreensão intelectual e do trabalho delimitado ao registro psíquico (ANTÚNEZ, 2012). Nesta mesma linha, a dor de alguns pacientes decorre da falta de abertura dos psicólogos para escutá-los no sentido que determinada experiência tem para eles (SAFRA, 2006). Safra (2006) relata observar o sofrimento de pessoas em consequência de tratamentos psicoterápicos orientados por perspectivas excessivamente reducionistas e abstraídas da experiência de vida. 
Os resultados destas pesquisas possuem em comum a visão de que a antropologia filosófica de Edith Stein oferece a fundamentação necessária para o enfrentamento destas questões no campo teórico e prático. Pudemos comprovar o mesmo a partir dos resultados de uma pesquisa empírica em psicologia clínica, realizada em um bairro da periferia de Salvador, na qual se buscou compreender o processo formativo dos moradores a partir da fenomenologia de Edith Stein; tendo em vista o fato de estarem inseridos em um contexto de violência e de forte expressão religiosa (CARNEIRO, 2016).

Dentre os avanços logrados com este trabalho pudemos constatar a fecundidade da descrição fenomenológica das vivências na forma como Edith Stein o faz. Trata-se de um pensamento vivo que extravasa a mera compreensão intelectual e suscita a vivência do "reconhecimento", uma vez que a estrutura da pessoa se revela com evidência e cuja aceitação é capaz de motivar um olhar para a própria interioridade, contribuindo para o autoconhecimento e para o conhecimento do outro (STEIN, 1999a, p. 79). Foi isso o que experimentamos pessoalmente e o que pudemos constatar pela devolutiva da pesquisa aos participantes. Apresentaremos a seguir trechos da análise desta pesquisa (CARNEIRO, 2016), de modo a ilustrar as contribuições de Edith Stein e o possível diálogo entre fenomenologia e psicologia em perspectiva social e clínica.

\section{Contexto de pesquisa}

A pesquisa ocorreu no bairro do Uruguai, na região conhecida como Alagados, em Salvador, por ter sido construído sobre a água, com palafitas. Com o tempo, o local foi sendo aterrado pelos próprios moradores, a princípio com lixo e restos de material de construção, e posteriormente com a ajuda do governo.

Duas particularidades do Uruguai nos chamaram a atenção e contribuíram para o interesse em realizar a pesquisa com os seus moradores. A primeira foi a visita do papa João Paulo II em 1980, ocasião em que foi construída a Igreja Nossa Senhora dos Alagados, hoje 
denominada Nossa Senhora dos Alagados e São João Paulo II, tendo sido a primeira igreja no mundo dedicada ao papa polonês. Esse fato, somado à presença de Irmã Dulce dos Pobres, que iniciou suas obras sociais no local e à visita de Madre Teresa de Calcutá, que ali fundou uma casa de sua congregação, confere ao bairro um forte sentido religioso.

A segunda particularidade foi a constatação de que a colina onde se localiza a Igreja Nossa Senhora dos Alagados era também conhecida como lugar de "acerto de contas" e "desova de corpos" por traficantes e policiais. Desse modo, o ponto de referência do sagrado era também um marco da violência, congregando em um único local a manifestação de dois aspectos extremos do humano. $\mathrm{O}$ contraste e a convivência entre o sagrado e a violência remetem ao modo como cada pessoa lida pessoalmente com essas dimensões e foi um dos critérios que motivou a escolha do bairro do Uruguai como local privilegiado para a compreensão do processo formativo em contexto de violência.

\section{Metodologia}

Foram realizadas vinte e duas entrevistas abertas com nove moradores antigos; dois sacerdotes missionários e onze jovens; sendo ao todo nove mulheres e treze homens ${ }^{3}$.

A análise foi realizada em duas etapas; a primeira com o foco no percurso individual de quatro participantes (selecionados de acordo com o grau de abertura e a profundidade das vivências relatadas); e a segunda, com o foco comunitário, ou seja, buscando identificar as vivências comuns entre todos os entrevistados. Apresentaremos a seguir os resultados da primeira análise, ilustrando-os a partir do percurso individual de três participantes: Helena, Juliano e Bruno ${ }^{4}$.

\footnotetext{
3 Projeto aprovado no Comitê de Ética do Instituto de Psicologia da Universidade de São Paulo e Plataforma Brasil.

4 Os nomes dos entrevistados são fictícios.
} 


\section{Helena}

Helena nasceu no interior da Bahia e é a filha mais velha de 10 irmãos. Veio para Salvador estudar e passou a morar no bairro, onde vive há 30 anos. Estava com 55 anos na época da entrevista, em 2013.

Aos 24 anos conheceu o pai de seus dois filhos, com quem teve um relacionamento conturbado. As tensões no relacionamento culminaram com uma tentativa de suicídio de Helena, em que ela se jogou da laje de sua casa. Após este episódio, se separou do companheiro e passou a morar na casa de sua madrinha de batismo, junto com os filhos. Nesta fase, viveu um processo de conversão religiosa. Começou a frequentar a Igreja Católica local, assumindo um papel de liderança tanto no contexto religioso como na comunidade de moradores em geral, participando ativamente dos projetos de melhoria do bairro. É uma figura forte e um pilar da comunidade. Poderíamos dizer, para usar a expressão de Edith Stein (1999a, p. 297), que ela é uma "sustentadora da vida comunitária" local.

\section{Juliano}

Juliano tinha 24 anos em 2015, quando a entrevista foi realizada. Morou no bairro dos 4 aos 19 anos. Convivia com os traficantes de sua rua desde pequeno, quando tinha que passar sozinho pelas "bocas de fumo" [sic] ao ir para a escola. Sempre sentiu muito medo. Aos 16 anos, esse medo se transformou em admiração. Começou a traficar. Conta que foi ganhando prestígio, passou a beber, usar drogas e a aspirar bens materiais que não conseguiria adquirir com seu salário. Aos poucos, o roubo passou a fazer parte de sua rotina, "como uma profissão" [sic]. Juliano acabou sendo preso ao assaltar o carro de um policial militar. Quase foi morto e seu companheiro foi atingido por três balas. Na prisão, Juliano se converteu ao cristianismo evangélico, decidindo deixar o crime. Hoje trabalha como guia turístico. 


\section{Bruno}

Bruno é francês, atualmente tem 61 anos e é sacerdote. Veio para o Brasil em missão pela sua Diocese na França, tendo permanecido no bairro de 2003 a 2008, como pároco local. Após um duro período inicial de adaptação, em que ficou gravemente enfermo, Bruno retomou suas forças motivado, sobretudo, pela missão de reconquistar a "Igrejinha do Papa" [sic], até então alvo de assaltos e ações violentas devido a sua localização estratégica. Seguindo uma "firme intuição" [sic] pessoal e enfrentando a resistência dos moradores, Bruno passou a morar na Igreja e, junto com a comunidade paroquial, deu início ao projeto do Reforço Escolar, que contribuiu para instaurar uma nova dinâmica de paz no local.

\section{Análise e discussão}

A análise do percurso pessoal destes três entrevistados nos permitiu identificar cinco vivências comuns que caracterizam um movimento próprio do processo formativo daqueles moradores. As vivências foram assim nomeadas: 1) vivências psicofísicas de forte intensidade; 2) vivência do limite pessoal; 3) vivência da escuta de si; 4) a vivência da luta interior; e 5) a vivência de uma decisão livre.

Temos um primeiro momento marcado pela presença de vivências psicofísicas de forte intensidade. Na obra Contribuições à fundamentação filosófica da Psicologia e das Ciências do Espírito, ao tratar das vivências puras, Stein (1999a) distingue três componentes de uma vivência: o conteúdo (aquilo que ela recebe), o viver este conteúdo (ou seja, o modo como ele é apreendido pela pessoa (bem-estar, mal-estar, e graus de intensidade diversos) e a consciência do viver (no sentido de dar-se conta).

Ao falarmos em vivências psicofísicas de forte intensidade, estamos nos referindo, portanto, ao segundo componente que é o viver, a intensidade do viver. Trata-se de um tipo de vivência em que há uma consciência clara do viver, ou seja, a pessoa se dá conta do que está vivendo uma vez que é algo intenso que não passa despercebido, e, ao mesmo 
tempo, tem dificuldade de tomar distância e refletir a respeito, o que seria uma consciência de segundo grau, própria da dimensão espiritual. Stein (1999a) afirma que a intensidade do viver também está relacionada à esfera vital (estado vital), ou seja, se estamos cansados, a intensidade do viver tende a ser baixa. Por outro lado, um alto grau de intensidade do viver pode estar relacionado tanto a um estado de frescor (quando os sentidos e as sensações estão aguçados) quanto ao estado febril ou de superexcitação (situações de estimulação muito forte, como, por exemplo, em atividades de grande responsabilidade, em uma situação de risco, em momentos decisivos na vida, ou sob influência de substâncias químicas estimulantes como a cafeína), que são os dois exemplos extremos dados por Edith Stein e que ilustram "vitalidades" de qualidades diferentes.

No nosso caso, ao falarmos em vivências psicofísicas de forte intensidade, referimo-nos às vivências próximas ao estado febril ou de superexcitação, e que estão relacionadas a situações de doença ou violência (assaltos, tentativa de estupro, ameaças) como ilustra o relato de Helena a respeito de um assalto que sofreu no ponto de ônibus quando ia para o trabalho. De acordo com o relato, um "ladrão" a atacou com uma faca após ela ter reagido ao assalto gritando para as outras pessoas que estavam no ponto. Ela descreve o momento da luta com o assaltante: "- Eu olhava bem no olho dele e quando ele fazia vir com a faca, eu jogava a bolsa e a faca pegava na bolsa".

É possível captar o alto grau de tensão em que Helena se encontrava e como estava totalmente desperta na situação, à semelhança da descrição de Stein (1999a) a respeito do estado de superexcitação: "as impressões são captadas com facilidade, as atividades são realizadas sem dificuldade, a consciência do viver é clara e o conteúdo pleno de vitalidade" (STEIN, 1999a, p. 54).

Por outro lado, como vimos, trata-se de uma vivência em que a reflexão não tem lugar. De fato, refletir implica certo distanciamento, o que só foi possível em um momento posterior à situação. Ao chegar em casa e se deparar com a mochila e as roupas rasgadas, Helena reconheceu o perigo. Afirma: “- Eu ia estar toda furada. Naquela noite eu não consegui dormir. Fiquei olhando a mochila..." 
Stein (1999a) nos ajuda a compreender esta vivência de Helena ao descrever o estado de "distensão doloroso" que acontece após uma situação de grande tensão. Trata-se de um movimento em que o viver não está receptivo às impressões, mas também não consegue se fechar. Neste sentido, o estado da pessoa pode ser descrito como o de uma "prostração que não atinge o repouso".

Também Bruno conta o duro período de adaptação ao chegar ao bairro às pressas para assumir o lugar do então pároco local. Conta que chegou sem preparo nenhum, sem ter tido tempo de conhecer a língua e nem a realidade do lugar. Afirma: "Aí tive que me virar. Eu fui jogado na água mesmo." Aprendeu tudo sozinho, observando e obedecendo os moradores nas situações de risco, conforme relata:

Tem momentos de tiro, momentos de resolução de conflitos, aí todo mundo tá preso nas casas, ninguém sai. Mas depois, quando pode, sai de novo, como depois da chuva. O pessoal aprende a viver com a violência. Eles sabem lidar [...] Eu não sabia, aprendi com eles. Ver todo mundo desaparecer num instante, do nada! Eles repararam num rapaz que está armado e vai resolver um conflito. Eles sabem. Aí eu obedecia quando me diziam: “Entra aqui!” (trecho da entrevista).

Bruno também conta que pegou dengue e precisou sair de sua casa devido às condições precárias. Segundo ele, o processo de adoecimento foi um fator a mais que dificultou sua adaptação, a integração com os moradores e a sua missão como pároco local. A este respeito afirma: "O povo não confiava em mim porque não sabia se eu ia sobreviver [...] as pessoas falavam muitas coisas." Conta que emagreceu muito, quase morreu!

Estes relatos ilustram, portanto as vivências psicofísicas de forte intensidade em que a pessoa se mobiliza, fica em estado de alerta para lidar com uma situação exigente (violenta) e o estado sucessivo é o de uma distensão dolorosa que não atinge o repouso e que muitas vezes vem acompanhado pelo aparecimento de sintomas como pressão alta, dor de cabeça, depressão etc.

A segunda vivência comum identificada foi a do limite pessoal em que a pessoa se dá conta da sua condição ontológica de ser mortal a 
partir de uma situação de morte iminente (risco iminente de perda da própria vida). No caso de Helena, as tensões no relacionamento conturbado com o pai de seus filhos culminaram com uma tentativa de suicídio, em que ela se jogou da laje de sua casa. Afirma:

Eu estava vivendo um processo muito difícil com o pai de meus filhos. Então, numa certa feita eu resolvi: os dois não dá pra viver juntos. Ou eu matava ele ou ele a mim. Num clima desses eu preferia até morrer [...] Aí eu tinha na minha cabeça que ele ia me matar naquele dia. Ele chegou do trabalho e começou umas conversas estranhas e eu botei na minha cabeça... Bom, ele vai me matar, então antes que ele me mate, eu vou matar ele. E fiquei com aquele negócio, entrava e saía com aquele negócio, eu imaginava né. Uma fixação. Aí eu disse: Eu não vou fazer isso não. Aí eu peguei e pulei. Caí no quintal do vizinho [...] Passei um dia e uma noite no sanatório, internada como doida [...] (trecho da entrevista).

Pelo relato, é possível perceber que o ato de se jogar da laje foi uma ação motivada e não simplesmente um lançar-se sem sentido. Neste caso, o motivo que desencadeou a ação foi o não querer matar o companheiro e, podemos dizer, a constatação de que não era livre para realizar tal propósito. De fato, Helena descreve que tinha um pensamento fixo ("Antes que ele me mate eu vou matar ele") e demonstra que não queria fazer isso ("eu não vou fazer isso") e ao mesmo tempo, parece ter se dado conta de que não podia responder por seus atos, ou seja, de que o "eu" não governava a situação. O ato mais livre que Helena conseguiu naquele momento foi se jogar para não se submeter a um impulso destrutivo em relação ao outro. Era preferível morrer, eliminar a si mesma do que eliminar o outro.

Julgamos importante essa análise porque permite adentrar minimamente na dinâmica pessoal de Helena e compreender a situação a partir de sua vivência e não dos fatos externos. Realmente se pensarmos no suicídio objetivamente, ele não nos parece um "ato razoável" no sentido apresentado por Stein (1999a), ou seja, no sentido de um comportamento motivado por um fundamento que o justifique, mas pela análise da vivência é possível ir além do rótulo "patologizante" a fim de compreender o sentido daquele ato para a pessoa. Isso não 
tira, entretanto, o valor objetivo da própria vida e o aspecto negativo de querer exterminá-la. Edith Stein nos ajuda nesta compreensão ao afirmar que "o motivo autêntico da ligação entre os atos não é o cumprimento do ato em si, mas o seu conteúdo de sentido" (STEIN, 1999a, p. 76). Sendo assim, um mesmo motivo pode suscitar diferentes atos. No caso de Helena, a saída possível nas condições de sofrimento e desespero em que ela se encontrava - diante dos condicionamentos a que estava submetida - foi a de pular.

Essa situação ilustra a importância da afirmação de Ales Bello (1999) de que é impossível compreendermos a psique se não levarmos em conta a dimensão espiritual da pessoa e a motivação. O entrelaçamento das diferentes esferas do viver nos auxiliam a não permanecer na superfície do agir, mas a adentrar na vida interior da pessoa, compreendendo os valores e sentidos que a mobilizam.

Ainda em relação à vivência do limite pessoal, temos o relato de Juliano, que quase foi morto ao ser pego por um policial durante um assalto. Ele relata:

Nesse dia foi como um milagre porque nós não fomos mortos [...] uma moradora local interviu e não permitiu que o policial nos levasse pra nos matar; e os policiais estavam com sede mesmo de nos matar [...] Isso nunca tinha acontecido comigo. Depois eu fui preso (trecho da entrevista).

Para os três entrevistados, o deparar-se com o limite pessoal motivou um movimento em direção à interioridade e à escuta de si, que definimos como a terceira vivência, em que o apelo do núcleo foi sentido e tomou a forma de um projeto pessoal. Juliano relata:

Eu tive essa experiência muito terrível na minha vida, de ser preso. Mas foi lá que eu tive a oportunidade de [...] acordar para a realidade que eu estava vivendo e decidir o que eu queria na minha vida: se eu queria realmente continuar nessa vida de trevas ou se eu queria uma mudança de vida (trecho da entrevista).

Helena também se deu conta do que havia vivenciado e teve a certeza de não querer mais isso para si. Ao mesmo tempo, se deu conta 
de não conseguir mudar sozinha; e diante do limite pessoal, realizou um ato de fé, confiando-se ao divino, ao Ilimitado: "Eu bem sentada naquele dia, fiquei assim olhando para o tempo, para o céu. Já estava escurecendo e eu me lembrei de tudo que eu tinha vivido aqueles meses antes, e eu não ia voltar tudo. Eu disse: 'Senhor agora, meu Deus, agora você tem que dar um jeito!'” (trecho da entrevista).

Helena viveu uma conversão religiosa que a levou a afirmar: "Deus me tirou do sepulcro" (trecho da entrevista).

Bruno também conta que ao pegar dengue ficou muito fraco e morou por quatro meses na casa das "irmãs da caridade", que fica ao pé da colina onde se localiza a Igreja Nossa Senhora dos Alagados. Por ser um local de muita violência, os padres não moravam na Igreja, mas em casas de paroquianos. Bruno conta que da janela de seu quarto na casa das irmãs enxergava a Igreja e sentia que devia se mudar para lá. Relata:

Estava todo dia olhando pra esse negócio em cima [a Igreja]. Falava pra mim mesmo: "Você não está aqui por nada, porque essa Igreja foi fundada pelo Papa". Minha vocação sacerdotal vem do Papa João Paulo II [...] Minha intuição era firme. Eu dizia: "Eu vou morar lá" (trecho da entrevista).

Foi motivado pelo reconhecimento de que a Igreja Nossa Senhora dos Alagados e sua vocação sacerdotal tinham uma raiz e um sentido comum, ou seja, a presença de João Paulo II ${ }^{5}$ e o legado por ele deixado.

Retomando a visão formativa de Stein (1999a), podemos compreender essa intuição de Bruno como uma manifestação da sua interioridade mais profunda, da força íntima que Stein denomina Gemuet e que compreendemos como uma capacidade do espírito de captar um valor. Trata-se da percepção de um sentido acompanhada de um movimento da vontade por reconhecer esse sentido como um bem. Esta parece ter sido a vivência de Bruno diante da visão da Igreja pela janela de seu quarto.

5 Destacamos neste ponto que Bruno sentiu 0 apelo ao sacerdócio também ao vivenciar uma situação-limite, embora não pessoal. Relata: “0 atentado do papa J.P. II, dia 13 de maio 1981 na Praça São Pedro em Roma durante a audiência da quartafeira foi o choque que me impulsionou para deixar meu trabalho e minha vida em Zürich na Suíça Alemã, onde morava neste período, para me decidir entrar no seminário". 
A quarta vivência identificada é a da luta interior entre o propósito de seguir o apelo do núcleo (vivência espiritual) e o "ego", identificado com o movimento psíquico de busca de bem-estar e de permanência no status quo, conhecido e, portanto, "seguro".

No caso de Bruno, parecia haver uma convicção firme e a luta não foi tanto interior, mas se deu principalmente pela resistência da comunidade local. Ele estava convicto, mas, segundo relata, por medo, as pessoas não quiseram dialogar. Bruno captou a força formadora da Igreja Nossa Senhora dos Alagados, ainda que seu brilho estivesse encoberto pela poeira da violência. Poeira esta que afetava as pessoas gerando medo e uma reação psíquica de fuga. A esse respeito Bruno relata que enfrentou muita resistência e que "ninguém quis saber desse diálogo. Foi tudo muito mal".

A sua vontade caminhava na direção oposta ao que os moradores viviam. Bruno propunha um ato que rompia com o modo próprio das pessoas vivenciarem a relação com a Igreja e com a violência. Rompia com um hábito instaurado, com a tradição de uma reação típica em relação à violência que era o silêncio e a fuga. Ao contrário, ele queria ocupar o local e dar um novo sentido para a colina; realizar o sentido que captara. Temos, portanto, de um lado, a intuição de Bruno de conquistar um bem da comunidade (um movimento do espírito), e de outro a resistência das pessoas a enfrentar o mal que o circundava, por medo (movimento psíquico).

Em Helena, a vivência da luta interior não foi identificada em um momento preciso, mas aparece em todo o seu percurso, e principalmente após a conversão religiosa, quando ela passa a se conhecer cada vez mais e a querer transformar seus hábitos de acordo com a ética cristã ("aprender a dialogar em vez de me impor"), ou ainda a luta contra momentos de tristeza em que não sente vontade de fazer nada, mas que, por amor ao outro (filhos, colega de trabalho), não deixa de levantar da cama e fazer o seu dever. Nesse sentido, a luta aparece como o esforço de dominar impulsos e tendências que ela sente como negativos.

Juliano, por sua vez, explicita a vivência da luta interior em uma situação específica na prisão. Conta que passou a "ser influenciado" pelo contato com cristãos evangélicos e que isso criou nele "um sentimento 
de revolução". Escutava que devia "multiplicar em vez de subtrair", "ter um procedimento melhor na sociedade", "ser uma nova criatura".

Por outro lado, relata que recebia muitas propostas para participar de grupos criminosos devido à sua experiência na área:

Bastava eu contar minhas experiências vividas antes de ser preso, que era motivo pra muitos me chamarem pra assumir certa liderança [...] eu já tinha um grau mais elevado no crime, eu já não era mais um iniciante, já era experiente em cometer assaltos, com experiência em fuga, sobrevivendo no crime [...] e isso era muito importante para o grupo: uma pessoa com o perfil, com experiência e disposição que não teria o medo de um iniciante (trecho da entrevista).

Além disso, ao aliar-se às facções da prisão, ele receberia regalias como a liderança de uma cela, colchão, lençol, roupas, material higiênico e outras coisas que eram muito difíceis para um "recém-chegado" adquirir, porque dependiam de visitas. Tudo isso foi vivenciado por Juliano como um "privilégio" e, ao mesmo tempo, como um "desafio" que deveria enfrentar para superar a influência do crime sobre ele. A esse respeito afirma:

Por um lado, eu tive o privilégio de ter essa regalia, mas por outro lado era algo que estava me chamando a integrar essa facção. Eu passei por uma luta mental muito grande. Eu tive que decidir ou ter a regalia e ao mesmo tempo fazer parte da facção; ou rejeitar a regalia e ir contrariamente à vontade da facção. Foi algo muito difícil nesse período (trecho da entrevista).

Juliano passou a vivenciar uma divisão e uma luta interior entre a liderança no crime e a vida que lhe era apresentada no grupo religioso.

Enquanto muitos estavam me chamando para continuar no caminho da criminalidade, a minoria estava me convencendo de qual caminho era o certo, de qual era a boa influência [...] Foi uma luta muito grande, eu tive que decidir entre a minha religiosidade e meu ego (trecho da entrevista). 
Estava dividido entre a atração psíquica e o bem-estar por um lado (ego) e, por outro, a atração a um caminho de fé que fora reconhecido com um bem para si, valorizado e compreendido (dimensão espiritual) como a possibilidade de uma nova vida; mas que implicava a renúncia a tudo o que havia valorizado, vivido e aprendido até então (renúncia ao ego). De fato, Juliano intuiu a religiosidade como um valor no sentido steiniano do termo, ou seja, como um elemento significativo para a sua formação (STEIN, 1999b). Captou nesta realidade um valor que o atraiu e que motivou nele "um querer e um agir, dando origem a um comportamento reconhecido como moralmente reto" (STEIN, 1999a, p. 75).

A transformação de Juliano não foi automática ou sem dificuldades, não foi a passagem definitiva de um extremo a outro (do criminoso ao cidadão exemplar, ou do pecador ao santo), mas se configurou como um processo sofrido em que sentimentos contraditórios o habitavam; em que as decisões oscilavam repercutindo em seu comportamento. Conta, por exemplo, que chegou a traficar na detenção mesmo depois de ter iniciado um processo de conversão religiosa na delegacia.

Evidencia-se, portanto, a constatação de Edith Stein (1999) de que conseguimos identificar e nomear estados da pessoa (tais como cansaço e frescor) que correspondem apenas a qualidades extremas e que não contemplam as inúmeras gradações intermediárias de um mesmo sentimento vital. Segundo a autora (STEIN, 1999), estas gradações podem ser comparadas às diferentes tonalidades de uma mesma cor, colocadas em evidência pelo pintor e não valorizadas pela linguagem cotidiana, que se limita à diferenciação de cores. Sendo assim, reconhecemos a limitação desta análise e compreensão à medida que as diversas esfumaturas dos estados vitais nos escapam. Por outro lado, é possível intuir e evidenciar a sua complexidade pela vivência da "luta interior".

Retomando a análise, Juliano foi questionado pelos líderes do tráfico a respeito de sua conversão, ou seja, foi questionado se esta seria fruto de uma convicção, ou se se tratava de uma simulação com o intuito de proteger-se. 
Tive que provar o que realmente eu queria para os criminosos. Então eu passei por dez semanas de provação onde eles olharam meu comportamento, se realmente eu estava procedendo conforme minha escolha, se queria realmente ser cristão. Foi aquilo que me fez focar. Comecei a me afastar das más amizades, a meditar a Palavra e a falar menos, a ajudar quem podia ajudar. Mas não foi muito fácil, foi difícil. Muitos deles andavam com rádio, com fone de ouvido fingindo que estavam ouvindo música, mas estavam no silencioso pra ouvir qual conversa eu estava tendo, se eu estava conversando sobre crimes, sobre sair e cometer crimes. Eu estava sendo testado diariamente, estavam tendo ordem de me testar. Se eu fosse pego em uma infração, em uma contradição, eu ia ser punido (trecho da entrevista).

Juliano teve que provar para os membros da facção que a sua adesão ao cristianismo decorria de uma posição assumida internamente pelo eu e não de um "simulacro" (STEIN, 2007, p. 522). Isso, de certa maneira, o forçou a afirmar para si mesmo esta posição e a realizar um ato livre e voluntário, ainda que sob ameaça. A este respeito Edith Stein afirma que "não podemos nos forçar para obter um ato livre, mas podemos nos propor a isso" (STEIN, 1999a, p. 88). Foi o que Juliano fez.

Finalmente, o quinto momento é marcado pela decisão livre de seguir o apelo do núcleo. Neste sentido, foi possível constatar a presença de um propósito, mas também de um "fiat", ou seja, de uma decisão tomada em um momento oportuno e que é responsável pela passagem do propósito ao ato (STEIN, 1999a, p. 89).

Bruno se mudou para a Igreja, seguindo a direção "intuída". Rompeu com um ciclo de medo e silêncio dos moradores em relação ao local. Afirma: "Celebrei a missa do Natal de 2003 em cima. E fiquei".

Afirma que, diante desse ato, a comunidade silenciou... "Ninguém dizia nada. A comunidade sem voz. Certeza de que iam me matar". Entretanto, afirma: "A história me deu razão. E, de fato, fui morar lá e ninguém me tirou até a mudança." O sentido desse ato se manifesta pela seguinte afirmação de Bruno: "Eu penso que devolvi a Paróquia à comunidade" (trecho da entrevista).

Juliano também afirma: "Eu escolhi sair de lá sem esse prestígio [da criminalidade], mas com minha fé." Conta que, ao sair da prisão, instalou-se em outra região da cidade e passou por um período de 
"purificação" (jejum e oração) em que lutava para romper com hábitos instaurados como roubar e traficar; um processo necessário para que a dimensão psicofísica fosse "conformada" à decisão espiritual (nova direção assumida interiormente). Atualmente Juliano trabalha na área do turismo e é voluntário em um projeto com jovens.

Nos três entrevistados, estas cinco vivências (vivências psicofísicas, limite pessoal, escuta de si, luta interior, decisão livre) marcaram um processo de transformação da pessoa e do contexto em que ela se insere. Elas ilustram um movimento formativo em que cada um passou a agir e intervir no mundo orientado por um projeto pessoal. Ou seja, tomaram consciência do vivido e conseguiram dar um sentido para esse vivido estruturando possibilidades de escolhas e perspectivas de vida para além do que estava dado; dando novo rumo para suas vidas de acordo com o apelo do núcleo (desenvolvimento da atividade espiritual).

\section{Considerações finais}

A análise apresentada não esgota as possibilidades de compreensão dos percursos pessoais dos entrevistados; mas sim, ilustra a importância do pensamento de Edith Stein, que nos impele a ir ao encontro de cada singularidade e complexidade; e nos ajuda a captar, a partir de uma estrutura comum, os movimentos pessoais e a potência que eles contêm, e que nem sempre se evidenciam em um contexto de vida em que situações extremas tendem a monopolizar nossa atenção (o que vale também para situações em psicoterapia, serviços de saúde mental e outras práticas psicológicas).

Edith Stein nos ajuda, portanto, a não reduzir a pessoa aos desafios do contexto em que vive ou aos condicionamentos psicofísicos aos quais está submetida, mas a enxergá-la na sua inteireza, discriminando as diferentes naturezas de vivências e o seu modo singular de viver. Neste sentido, a fenomenologia de Edith Stein contribui para o amadurecimento da psicologia, oferecendo subsídios para a superação de visões ingênuas, generalistas e, portanto, reducionistas do outro. 
O rigor e a força de um pensamento vivo como o de Edith Stein se manifestam pela vivência do reconhecimento, quando as suas descrições se revelam a nós com evidência e encontram uma ressonância interior que é transformadora. Daí a fecundidade deste pensamento no campo da psicologia.

\section{Referências}

ALES BELLO, A. Presentazione. In: STEIN, E. Psicologia e Scienze dello Spirito: Contributi per uma fondazione filosofica. Trad. A. M. Pezzela. Roma: Città Nuova, 1999. p. 5-32.

ALES BELLO, A. Percurso de um psiquiatra. Trad. M. L. Fernandes. Revista PistisEPraxis: Teologia Pastoral, v. 3, n. 2, p. 541-554, 2011.

ALES BELLO, A. L'eredità di Ludwig Binswanger in Bruno Callieri. Rivista Comprendre, n. 23, 2013-I.

ALES BELLO, A. Pessoa e comunidade: comentários: psicologia e ciências do espírito de Edith Stein. Trad. M. Mahfoud; J. T. G. Garcia. Belo Horizonte: Artesã, 2015.

ANTÚNEZ, A. E. A. Perspectivas fenomenológicas em atendimentos clínicos: humanologia. Tese (Livre Docência) - Departamento de Psicologia Clínica, Instituto de Psicologia, Universidade de São Paulo. São Paulo, 2012.

CALLIERI, B. Nihil est praeter individum. In: ALESBELLO, A; MANGANARO, P. (Orgs.). ...E la coscienza? Fenomenologia, psico-patologia, neuroscienze. CerchiConcentrici, collana del Centro Italiano di Ricerche Fenomenologiche. Bari: Edizioni Giuseppe Laterza, 2012. p. 635-660.

CARDOSO, C. de R. D. Contribuições de Edith Stein para a epistemologia das ciências e para a psicologia científica. Dissertação (Mestrado em Psicologia) Departamento de Psicologia, Faculdade de Filosofia, Ciências e Letras de Ribeirão Preto, Universidade de São Paulo, Ribeirão Preto, 2012. 
CARNEIRO, S. F. B. A formação humana em contexto de violência: uma compreensão clínica a partir da fenomenologia de Edith Stein. Tese (Doutorado em Ciências: Psicologia Clínica) - Instituto de Psicologia, Universidade Estadual de São Paulo, São Paulo, 2016.

SAFRA, G. Hermenêutica na situação clínica o desvelar da singularidade pelo idioma pessoal. São Paulo: Edições Sobornost, 2006.

SILVA, N. H. L. Saúde Mental na Estratégia de Saúde da Família: uma compreensão a partir da fenomenologia de Edith Stein. Tese (Doutorado em Ciências: Psicologia) - Faculdade de Filosofia, Ciências e Letras de Ribeirão Preto, Universidade Estadual de São Paulo, Ribeirão Preto, 2011. Disponível em: $<$ http://www.ffclrp.usp.br/imagens_defesas/25_01_2012_09_58_39_61.pdf>. Acesso em: 22 fev. 2017.

STEIN, E. Psicologia e scienze dello spirito: contributi per una fondazione filosofica. 2. ed. Apresent. A. Ales Bello; Trad. A. M. Pezella. Roma: Città Nuova, 1999a.

STEIN, E. La vita come totalità: scritti sull'educazione religiosa. Trad. Tereza Franzosi. Roma: Città Nuova, 1999b.

STEIN, E. El ser humano. In: STEIN, E. Potência e Ato. Burgos: Monte Carmelo; Espiritualidad; El Carmen, 2007. Obras Completas, v. III: Escritos filosóficos: etapa de pensamiento cristiano: 1921-1936, p. 484-528.

Recebido: 15/09/2017

Received: 09/15/2017

Aprovado: 06/10/2017

Approved: 10/06/2017 